\title{
Research on Industrial Cluster and Regional Economic Growth
}

\author{
Lixiao Wang \\ Northwest University, Xi'an, Shaanxi, 710127 \\ Xi'an Fanyi University, Xi’an, Shaanxi, 710105
}

Keywords: industrial cluster; regional economic growth; China economy

\begin{abstract}
Industrial clusters are new economic phenomena arising from economic development. The accumulation of such large enterprises and related institutions in certain areas reduces the average cost of the industrial clusters on the one hand, and reduces the average cost of individual enterprises in the clusters on the other hand, forming the intangible assets of industrial cluster. With the accumulation of regional industries, specific regions affect the economic growth of the region through changes in the stock of intangible assets.
\end{abstract}

\section{Introduction}

Due to the differences in geographical forms, the uneven spatial distribution of natural resources, and the different economic growth bases of various regions, China's regional economic growth is unbalanced. Therefore, it is necessary to study the growth of the economy based on specific factors that affect regional economic growth. Economic growth generally refers to the sustainable growth of national wealth or social wealth, that is, the growth of gross domestic product (GDP) without damaging the environment and standard energy consumption. The sustainable growth of regional GDP depends on the quantity and quality of regional human resources, the quantity and quality of natural resources and capital stock, and the level of regional science and technology. On the other hand, the sustainable growth of regional GDP and regional industrial agglomeration 1 Or industrial clusters are closely related. Industrial agglomeration or industrial cluster refers to the economic phenomenon formed by the accumulation of a large number of enterprises and related supporting and service organizations in a certain area in a geographical space. Since the 1970s, with the rapid development of the traditional industrial clusters in northern Italy and their comparative advantages in international competition, the phenomenon of industrial clusters has attracted people's attention. After the 1980s, with the US Silicon Valley and 128 Highway Electronics Industry Cluster, Massa's clogged footwear industry cluster, Germany's Tuttlingen's surgical equipment industry cluster, Stuttgart's machine tool industry cluster, Vegera's optical instrument industry cluster The fragile glass bottle industry cluster in the Breer Valley of France and the vigorous development of the network industry cluster in the Sundil district of Paris make the industrial cluster become the highlight of the attention of governments and regional academic circles. In China, with Beijing Zhongguancun Electronic Industry Cluster, Zhejiang Zhangzhou Tie Industry Cluster, Fujian Sports Shoes Industry Cluster, Guangdong Furniture Industry Cluster, Jiangsu Textile Industry Cluster, Yunnan Tobacco Processing Industry Cluster, Chongqing Motorcycle Industry Cluster The development of such industries and the important role these industrial clusters play in regional economic growth, the economic phenomenon of industrial clusters has also become the focus of attention in China's regional economics community. Therefore, in China, it is necessary to study the relationship between industrial clusters and regional economic growth. To study the relationship between industrial clusters and regional economic growth, on the one hand, we can theoretically explore the relationship between industrial clusters and regional economic growth, in order to expand the study of industrial clusters and regional economic growth; on the other hand, we can conduct Industrial layout and promotion of regional economic development propose practical guidance for practicality. Therefore, the research on this topic not only has important theoretical significance, but also has far-reaching practical significance for coordinating regional economic 
development in China.

\section{Characteristics of Industrial Clusters}

With the US Silicon Valley Information Industry Cluster, the software industry cluster in Bangalore, India, and China's domestic Zhongguancun Electronics Industry Cluster, Fujian's sports shoes, umbrella industry cluster, Guangdong's furniture industry cluster, Jiangsu's textile industry cluster, Yunnan's tobacco processing industry The development and expansion of clusters and motorcycle industry clusters in Chongqing, the phenomenon of industrial clusters has become the focus of domestic and foreign economists research, they have analyzed and studied the economic activities of industrial clusters from different perspectives. These studies have expanded the connotation and extension of industrial clusters. The main manifestation is that industrial clusters not only refer to the phenomenon that regional related enterprises gather in groups to gain competitive advantage, but also include related institutions such as banks, consulting, universities, research institutions, insurance, chambers of commerce, and government. The geographical proximity of various units, including institutions.

There are forward, backward and horizontal network partnerships in industrial clusters. This network includes enterprise production factor market networks, technologies, information networks, and regional innovation networks. Trade, non-trade transactions, exchanges and interactions between network entities. Constantly provide impetus to business development and innovation in the network. On the other hand, enterprises in industrial clusters have both large enterprises and small and medium-sized enterprises. They are not simply approached and concentrated in a certain area, but are associated with a certain value-added production chain to form a specialized industrial chain. From the perspective of forward, backward and horizontal network cooperation between industrial cluster enterprises, enterprises in industrial clusters not only include upstream raw material supply, machinery and equipment manufacturing, spare parts production and service supply enterprises, but also downstream products. Vendors, their networks, customers, etc., at the same time, can be extended to manufacturers of complementary products, related technologies such as technical and technical training and industry intermediaries, and public goods manufacturing enterprises such as infrastructure, thus forming a division of labor and collaboration. The network body linked by the industrial chain. Enterprises in industrial clusters have super-liquidity in terms of technology, knowledge, capital, talents, information and other factors required by enterprises in industrial clusters due to the orderly division of labor and close production coordination. This ultra-liquidity includes the rapid flow and integration of people and institutions, the rapid flow of capital and technology, the rapid flow of information between suppliers, manufacturers, and users, as well as from market research, product design, product manufacturing, and product sales. The rapid flow and delivery of information between the various links until the product is finally used by the consumer. The rapid flow of elements in industrial clusters can quickly bring together elements and combine them in a short period of time, so that the output efficiency of enterprises in industrial clusters can reach a higher level at any time according to market needs. At the same time, the effective and rational super-liquidity of the elements in the industrial cluster, in turn, is conducive to the development and rapid growth of the entire industrial cluster.

\section{Conditions for the Formation of Industrial Clusters}

Products produced by companies in industrial clusters have a long value chain. The entry of new enterprises is the key to the sustainable competitive advantage of industrial clusters. The long value chain provides the basis for the emergence and division of labor of new enterprises. The longer value chain is mainly characterized by the existence of a large number of process-oriented enterprises and intermediate product trading markets in the region. Such as Chongqing's motorcycle industry cluster. Motorcycle production can be divided into tires, frames, shelves, gasoline engines, lights, ignition systems and other parts of the production, each component has 3 to 5 companies, according to survey statistics, only formed in the Chongqing area more than 500 Small motorcycle 
parts companies, these motorcycle parts gathered and concentrated to form a motorcycle parts industry cluster. In general, the longer the product value chain, the greater the possibility of technical decomposition of the process, and the longer the vertical division of labor, so that the conditions for industrial clusters are more sufficient.

Industrial cluster enterprises have a large space for product differentiation. Product differentiation refers to the difference between products of the same function. This difference includes product differences in the horizontal and vertical directions. On the one hand, product differentiation in the horizontal direction refers to differences in product specifications, varieties, colors, raw materials, grades, brands, etc. On the other hand, vertical differences Chemicalization refers to the difference in the intrinsic quality of the same product. The potential for product differentiation of industrial cluster enterprises is mainly reflected in the horizontal direction, that is, product differentiation mainly occurs in the appearance of products, rather than in terms of the actual functions and efficiency of products. This product differentiation is largely dependent on the careful design of the product, and high design strength is a typical feature of cluster enterprise products. For example, in order to stimulate the demand of perfumes, the French perfume glass bottle industry cluster hired famous designers to design glass bottles to achieve product differentiation, which is conducive to improving the competitiveness of products and creating new consumer selling points. Many enterprises that produce similar products are close in the region. If there is not enough room for product differentiation, these enterprises will fall into a situation of vicious price competition, which will not be conducive to the formation and development of industrial clusters.

The globalization of the downstream products (mainly final products) of industrial cluster enterprise products. Industrial clusters are high-density concentration of enterprises in specific regions, which makes the supply of downstream products of the entire industrial cluster enterprises inevitably larger than the local consumer demand. This situation requires that their products must be sold to other countries or regions. If market size constraints occur within a particular region, there is no way to form a large number of firms that may be clustered in specific regions.

\section{Empirical Study on Industrial Clusters and Regional Economic Growth}

The industrial clusters in the west are not only low in concentration, but also slower in the rate of industrial agglomeration than in the east and coastal regions. As the concentration of non-equilibrium in the eastern and western industries intensifies, the economic growth of the eastern and western regions brought about by industrial agglomeration The gap is also expanding. From the empirical model, we can get: First, the regional economic growth rate is positively correlated with the enterprise unit number agglomeration index, the industrial value added agglomeration index, and the capital agglomeration index. It can be seen from the model (7.9) that when the unit number of enterprises increases by one unit, the regional economy will increase by 0.153 percentage points; when the capital accumulation index increases by one unit, the regional economy will increase by 1.42 percentage points. In addition, with the concentration of regional workers, regional economic growth will decline. According to the results of the model, when the regional employee concentration index increases by 1 unit, the regional economic growth will fall by 0.11 percentage points. Second, to promote regional economic growth, on the one hand, it can increase the output of existing enterprises in the region, and have a high output rate of enterprises, which is conducive to the concentration of industries; on the other hand, promote enterprises or industries through the formulation of relevant policies. The agglomeration will increase the concentration of the industry and thus the growth of the regional economy. In fact, the practice of the development of the Silicon Valley Industry Group, the French perfume glass bottle industry group, the Guangdong furniture industry group, the Beijing Zhongguancun Electronics and Computer Industry Group, and the Chongqing motorcycle industry group will prove that it will be beneficial to accelerate the cultivation of regional industrial clusters. Promote regional economic growth. 


\section{Conclusion}

The formation and development of industrial clusters cannot rely solely on external capital and regional natural resource endowments. Instead, various actors in the industrial cluster should establish long-term stable relationships through intermediaries and form a cooperative network to form a unique region. The economic environment to foster the development of industrial clusters; the small scale of enterprises is a common problem in China's regional development. Although many small enterprises have some difficulties, these difficulties exist not because of their small size, but because of their Isolation and separation, if these companies can be promoted to strengthen cooperation on the basis of specialized division of labor, small enterprises can fully improve their ability to innovate and compete.

\section{Acknowledgements}

Scientific Research Program Funded by Shaanxi Provincial Education Department (Program No. 17JK0973): "the Belt and Road" Stategic effect on the linkage development of economy in Shaanxi province and remodeling pattern; Xi'an Social Science Fund Project (18J216): Research on the construction of intelligent collaboration platform for Xi'an inland port in ABC era; Shaanxi Provincial Bureau of Statistics Project (LZ201807): Based on the five new concepts to build Shaanxi Datongguan intelligent platform research; Xi'an Fanyi University Team Construction Project (XFU17KYTDA02): Industrial docking study of the Silk Road Economic Belt.

\section{References}

[1] Sheng Yajun. The domain name plate based on the cluster angle of view forms the influence factor [J]. Management Review, 2009, 21 (3): 73-79.

[2] Li Dalei. The impact of the creation of industrial cluster branding [J]. Economic Management, 2009, 31 (3): 18-22.

[3] Hu Dalong. Corporate brand and regional brand interaction [J]. Economic Management, 2006, (5): 44-48.

[4] Xia Zengyu. Discussion on regional brand building China Industrial Economy, 2006, (10): 43-48.

[5] Liu Wei. The industry clusters under the perspective of cluster brands can continue to develop research [J]. Scientific Management Research, 2008, 26(5): 55-58. 